
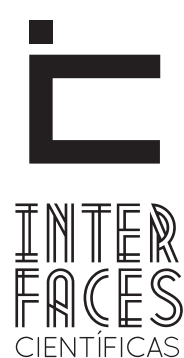

EDUCAÇÃO

ISSN IMPRESSO 2316-333X

ISSN ELETRÔNICO 2316-3828

DOI 10.17564/2316-3828.2015v3n3p77-86

\title{
CHILDREN OF DEAF ADULTS: CODAS EM SERGIPE
}

Alda Valéria S. de Melo ${ }^{1}$

\section{RESUMO}

O estudo apresenta uma investigação acerca dos Children Of Deaf Adults (CODAs) em Sergipe. Adotando como procedimento metodológico a revisão bibliográfica e uma pesquisa de campo. A referida pesquisa foi realizada formalmente com uma entrevista semiestruturada comum a CODA e seus pais surdos. A proposta surgiu a partir de encontros com surdos que frequentaram a Associação de Pais e Amigos - APADA/SE durante a década de 1990 e hoje encontram-se casados, com filhos ouvintes e que em diversas situações atuam com tradutores e intérpretes de Libras; e de leituras de artigos acerca de CODAs no Brasil, bem como portugueses e catalães. Como resultado, verificou-se que os CODAs possuem papel relevante para a inclusão do surdo, uma vez que conhecem as duas culturas, e diante desta realidade seu papel, também, se confunde com a do tradutor intérprete, o que deve ser repensado e discutido com mais profundidade, considerando as especificidades do profissional.

\section{PALAVRAS-CHAVE}

CODAs. Língua de Sinais. Pais Surdos. 


\section{ABSTRACT}

The study presents an investigation about the CODAs in Sergipe. The methodological procedure adopted is the literature review and a fieldwork. This research was carried out formally with a semistructured interview with CODAs and their deaf parents. The proposal came from meetings with deaf who attended the Parents and Friends Association - APADA-SE during the 1990's and currently are married, have children that listen and are able to be Libra translators and interpreters in various situation; and reading of articles about Children of Deaf Adults in Brazil a well as Portuguese and Catalan. As a result, it was found that the CODAs have an important role for the deaf inclusion, since they know both cultures, and on this reality its role is confused with the interpreter translator, which must be rethought and discussed deeply, considering the professional specificities.

Keywords: Children of Deaf Adults. Sign Language. Deaf Parents.

\section{RESUMEN}

El estudio presenta una investigaciónsobre dos CODAsen Sergipe. Adoptando como procedimiento metodológico larevisión bibliográfica y estudios de casos. La referida pesquisa fue realizada formalmente con una entrevista semiestructuradacon una CODA y sus padres sordos. La propuestasurgió a partir de encuentrosconsordos que frecuentaronlaAsociación de Padres y Amigos _ APADA/SE durante la década de 1990 y hoy se encuentran casados, conhijosoyentes y que en diversas situacionesactúancontraductores e intérpretes de Libras (LenguaBrasileña de Señales); y de lecturas de artículos sobre CODAsen Brasil, así como portugueses y catalanes. Como resultado,se verificó que losCODAsposeenpapeles relevantes para lainclusióndelsordo, una vez que conocenlas dos culturas, y delante de esta realidadsu papel también se confunde conladeltraductor intérprete, lo que debe ser repensado y discutido con más profundidad, considerando las especificidades delprofesional.

\section{PALABRAS CLAVE}

CODAs. Lengua de Signos. Padres Sordos. 


\section{INTRODUÇÃO}

Este artigo é uma investigação acerca dos Children Of Deaf Adults (CODAs) em Sergipe. Realizamos um estudo de caso, abordamos o processo de aquisição da Língua de Sinais e sua relação com a comunidade surda, considerando a diversidade cultural. 0 referido trabalho foi motivado a partir de encontros com surdos que frequentaram a Associação de Pais e Amigos (APADA)/SE durante a década de 1990 e hoje encontram-se casados, com filhos ouvintes e que em diversas situações atuam com tradutores e intérpretes de Libras.

E a partir de leituras de artigos acerca de CODAs no Brasil, vieram-nos à tona alguns questionamentos: como estes jovens adquiriram a Libras? Por que atribuem aos CODAs a função de tradutores e intérpretes de Libras²? Quanto à sua relação com a comunidade, uma vez que não são surdos, foram acolhidos?

Esta pesquisa tem o caráter qualitativo e utilizamos fontes bibliográficas, documentais e uma pesquisa de campo. A pesquisa de campo foi realizada formalmente com três entrevistas semiestruturadas com uma família de pais surdos em Sergipe.

Primeiro, apresentaremos um panorama da Comunidade Surda em Sergipe e a disseminação da Língua de Sinais. Em seguida, um estudo de caso de um CODA e seus pais surdos em Sergipe. Ressaltamos que será utilizada a expressão CODA - Crianças de pais surdos -, utilizada pela Organização Internacional CODA.

\section{A COMUNIDADE SURDA EM SERGIPE E A LÍNGUA DE SINAIS}

A identidade de um povo é a alma da sua cultura. (Joana Sousa).

2. Pessoa que traduz e interpreta a Língua de Sinais para a língua falada e vice-versa em quaisquer modalidades que se apresentem (oral ou escrita) (QUADROS, 2005, p. 10).
A Associação dos Surdos em Sergipe foi fundada em 1989, a princípio realizavam reuniões para confraternização. Apesar de usarem a Língua de Sinais como forma de comunicação, o número de sócios era pequeno, adultos em sua maioria. Em 1991 foi fundada a APADA, possivelmente devido ao seu objetivo, também pedagógico, atraiu um grande número de jovens que se reuniam regularmente.

\begin{abstract}
No mesmo ano, a sede da APADA foi transferida para um espaço mais acessível, o que favoreceu a realização de reuniões com surdos, aos sábados; os mais velhos participavam, juntamente com os jovens, havia bate papo, encenação teatral e oficinas de Libras colaborando, assim, para a construção de uma identidade dos surdos e o consequente reconhecimento deles enquanto comunidade. (MELO, 2013, p.16-17).
\end{abstract}

Verificamos que "os surdos mais velhos conheciam a Língua de Sinais e até tiveram oportunidade de conhecer as principais instituições do país ligadas à comunidade surda; no entanto, os mais jovens a desconheciam, aprendiam através de convivência" (MELO, 2013). Outrossim, constatamos que no período alguns surdos representantes da Federação Nacional dos Surdos (FENEIS) vieram a Aracaju para ministrar cursos, convidados pela Secretaria de Estado da Educação e pela APADA, e isso favoreceu para que a comunidade despertasse.

A Associação passou a ser vista com relevância e os surdos a frequentarem o espaço, que não era um local fixo, organizado em alguns momentos em associação de moradores ou em residências dos próprios membros. A comunidade começou a participar de eventos regionais organizados por associações em Pernambuco e Bahia, assim como contribuiu para a regulamentação da Língua de Sinais; iniciadas em 1995, em Sergipe foram recolhidas assinaturas que foram anexadas ao projeto de Lei aprovado em 2002.

Art. $1^{\circ}$. É reconhecida como meio legal de comunicação e expressão a Língua Brasileira de Sinais - Libras e outrosrecursos de expressão a ela associados. Parágrafo único. Entende-se como Língua Brasileira de 
Sinais - Libras a formade comunicação e expressão, em que o sistema linguístico de natureza visual-motora, com estrutura gramatical própria, constitue um sistema linguístico de transmissão de ideias e fatos, oriundos de comunidades de pessoas surdas do Brasil. (BRASIL, 2002).

Esse período foi muito importante, pois proporcionou um amadurecimento dos surdos enquanto comunidade, as primeiras experiências efetivamente com tradutores e intérpretes, ou seja, há uma compreensão da existência do profissional, apesar de não haver sua regulamentação. No entanto, observa-se que nos primeiros agrupamentos da comunidade não era uma prática a presença dos filhos (ouvintes) de surdos, pelo contrário, sua participação só ocorria em situações específicas como festas. Referimo-nos àqueles surdos mais idosos, alguns já falecidos, e que muito contribuíram para a organização dos surdos e disseminação da Libras em Sergipe. A prática de membros da família, mais especificamente os filhos, vem dos surdos jovens de 1990, que aprenderam a Libras na comunidade e hoje se encontram casados e compreendem a relevância da Língua de Sinais para sua inclusão social, seus filhos conhecem e passam, em diversas situações, a atuar como tradutores e intérpretes para seus pais.

\section{CODAS EM SERGIPE}

\section{Estas crianças são, talvez, dentro da comunidade surda, únicas, na forma como vivem.}

(Joana Sousa)

Historicamente podemos constatar que, no Brasil mais especificamente, as primeiras pessoas a mediar a comunicação entre surdos e ouvintes eram membros da família. Em Sergipe estas mudanças são evidentes na década de 1990.

A grande maioria desses surdos tiveram contato com a língua de sinais e a utilizaram em associações de surdos e outras organizações. Dentro desses espa- ços, os CODA s, que são trazidos, geralmente, pelos pais e familiares, crescem junto com outras crianças e adultos surdos, exercitando assim, a língua e sua cultura. (QUADROS, 2007, p. 245).

A palavra CODA significa Children Of Deaf Adults, ou seja, filhos de pais surdos, e é um termo utilizado pela Organização Internacional CODA. Para Sousa (2012, p. 404) "[...] estas crianças podem ser surdas ou ouvintes, uma vez que o que os faz serem CODA é o facto de terem pais surdos, ou terem sido educados por pessoas surdas". Nossa investigação está centrada nos CODA ouvintes. Eles têm acesso às duas línguas, isto é, a Língua de Sinais e a Língua oral. Para conhecer com profundidade as duas línguas é necessário mergulhar na cultura surda e na ouvinte, é o que ressalta Santos (2006), permear as múltiplas identidades, vivenciando, ao mesmo tempo, a realidade do mundo dos ouvintes e a realidade da cultura surda. Os CODAs são pessoas bilíngues e biculturais, pois dominam duas línguas e vivem entre duas culturas.

A aquisição da Língua de Sinais se dá pelo contato com os pais e com a comunidade surda, enquanto que a Língua oral na escola e no convívio com familiares ouvintes. Conforme afirma a CODA Viviane Santos Matos (2014):

\footnotetext{
Minha mãe se preocupou em me ensinar desde cedo, pois ficava mais fácil para ela me compreender, pois eu tentava falar e ela não conseguia me entender, então sinalizando tudo ficava mais fácil. Já a língua oral foi principalmente com minha família por parte de mãe. Minha tia disse que tinham a preocupação em saber se eu ouvia e sabia falar.
}

O CODA em algumas situações pode assumir a responsabilidade, para a qual na maioria das vezes não está preparado. Sousa (2012) diz que o sentido de responsabilidade é assumido muitas vezes pelos CODAs, significando ter de 'tomar conta dos pais', ou seja, assumir responsabilidades em idades desadequadas. Esta ideia surge, muitas vezes, por parte de familiares, que sendo ouvintes, consideram que 
a criança terá que cuidar dos pais, pois são surdos. No depoimento recolhido verificamos uma situação curiosa na qual a afirmativa é feita pelos pais: "você é nossa audição". Possivelmente não havia, no discurso, a intenção da responsabilidade de cuidar da família, mas o compromisso da informação com fidelidade a não omissão dos acontecimentos.

“[...] Com um ano de idade já pedia tudo, já se comunicava. Então meu esposo afirmou que deveríamos ensinar mais Libras, pois iríamos precisar dela [...]" (VALÉRIA MATOS, 2014). Neste depoimento constatamos a aceitação do CODA pela comunidade surda. Possivelmente torna-se naturalmente aceitável, uma vez que os CODAs são levados por seus pais surdos à comunidade e este contato favorece, como afirma Quadros (2007): “A empatia de uma CODA é um processo de abertura ao conjunto de problemáticas vistas a partir de ângulos comuns aos surdos. [...] Os CODAs são vistos como possíveis 'pontes' entre os mundos surdo e ouvinte".

Durante a entrevista, os pais deixaram claro que ensinar a Língua de Sinais para a filha seria também uma forma de unir a família: "[...] era importante, pois a aproximou da gente, nos comunicava" (VALÉRIA MATOS, 2014). No discurso da família fica nítido que a aprendizagem aconteceu naturalmente dentro de um contexto familiar amoroso. Para Quadros (2007, p. 249), "o coda se constitui com ambas estruturas linguísticas que se mesclam e interagem na constituição de sua subjetividade, especialmente quando a experiência com o bilinguismo se dá sem a violência colonial e o recalque da Língua de Sinais".

Conforme relata Valéria Santos Matos, surda, mãe de Viviane Santos Matos: "Minha irmã me ajudou falando com ela, com oito meses comecei a ensinar sinais 'água' e com um ano ela já sinalizava (pedia) tudo, nós nos comunicávamos”. Para Sousa (2012) o bebê, antes mesmo de pronunciar a primeira palavra, inicia a sua comunicação com o mundo por meio do balbuciar e do apontar. Este apontar, em famílias sur- das, será o início de uma verdadeira viagem ao mundo dos surdos e da língua gestual. A criança nascida no seio de uma família surda terá como sua primeira língua a língua dos seus pais - a língua gestual.

Outro aspecto relevante trata-se de que, para a maioria das pessoas, o fato de ser filho de surdos dá ao CODA o mérito de ser tradutor e intérprete de Libras, pela habilidade do mesmo em dominar a Língua de Sinais e conviver com a comunidade surda. Indagando este papel, foi questionado à CODA se sua atuação na comunidade se caracterizava como de tradutor e intérprete. Ela afirmou positivamente, considerando que ela é a voz dos pais e dos amigos de seus pais surdos, quando solicitada.

\begin{abstract}
Sim, porque em qualquer situação sou eu quemfalo. Quando estou com meus pais penso em Libras para informá-los melhor... já acostumei, faço isso desde pequena. Com os amigos deles também, eu os ajudo desde resolver alguma situação (problema) até telefonar para eles. (VIVIANE MATOS, 2014).
\end{abstract}

Ao fazer a mesma pergunta aos pais, eles também acenaram que sim, que a filha é uma tradutora e intérprete, mas ressaltaram que há limitação, ainda, na Língua de Sinais: "Ela é um pouco, pois sabe poucos sinais, ainda tem dificuldades", afirma a mãe.

\begin{abstract}
Como os CODAs usavam língua de sinais, eles tornavam-se intérpretes compulsoriamente, pelo menos para as próprias famílias. Para as famílias surdas, os CODAs são vistos como possíveis "pontes" entre os mundos surdo e ouvinte. Nageração do CODA entrevistado, as famílias surdas desejavamintensamente ter intérpretes dentro da família para "ajudá-los"a conectar-se com o mundo ouvinte. Isso pode ser entendidocom um sentimento beneficente (advocate feeling), assim comomencionado por Preston (1995). No presente caso, os valoresdas línguas são colocados e nessa família surda a língua de sinais é muito importante e o CODA a herda. (QUADROS, 2007, p. 261).
\end{abstract}

Não há dúvidas de que tais aspectos são relevantes, mas outros aspectos precisam ser considerados, como "a experiência de conviver com a língua de sinais normalmente, para os CODAs, fica restrita ao am- 
biente familiar" (QUADROS, 2007), para que um indivíduo seja considerado tradutor e intérprete de libras, conforme ressaltam Sander (2000), Quadros (2004) e Rosa (2005), a formação acadêmica é necessária para o exercício desse profissional.

Para melhor definir o perfil e qualificar o profissional tradutor e intérprete de Libras, a Universidade Federal de Santa Catarina (UFSC), em parceria com o Ministério de Educação, criou o primeiro programa de Língua de Sinais na própria Universidade, com a meta de formar professores de Libras e tradutores e intérpretes. Este curso também foi ofertado em oito estados do Brasil (Amazonas, Ceará, Bahia, Goiás, Rio de Janeiro, São Paulo, Rio Grande do Sul e Santa Catarina) e no Distrito Federal. Segundo Pires (2000, p. 86), “[...] interpretar é um ato complexo que exige, sobretudo, conhecimento teórico na área, pois somente a prática cotidiana não garante uma interpretação com qualidade". É preciso considerar que o fato de conviver com o surdo não garante ao CODA ser um tradutor e intérprete de Libras, se faz necessário uma formação acadêmica específica.

\section{CONCLUSÃO}

As possibilidades desta pesquisa não se encerram aqui. Ao contrário, a realização da mesma pode abrir possibilidades de novas investigações, de novas inquietações.

Essa pesquisa teve como objetivo investigar acerca dos CODAs em Sergipe, para tanto tivemos a colaboração de uma família de surdos que possuem uma filha ouvinte. A princípio a entrevista seria realizada somente com a CODA, mas o envolvimento da família durante a entrevista proporcionou informações que enriqueceram o trabalho. Os depoimentos forneceram informações acerca do processo de aquisição de duas línguas numa perspectiva bilíngue pela CODA, na importância dos CODAs como "pontes" entre os mundos: surdo e ouvinte, e a concepção de tradutor e intérprete de Libras no referido contexto. Esse encontro foi uma experiência singular, foi constatada uma parte do mundo surdo que ainda não foi estudado com a devida dedicação.

\section{REFERÊNCIAS}

BRASIL. Presidência da República. Lei n0 10.436, de 24 de abril de 2002. Dispõe sobre a Língua Brasileira de Sinais-LIBRAS e dá outras providências. Brasília, 2002.

MATOS, Valéria Santos. Entrevista, concedida em 5 de julho de 2014 a Alda Valéria Santos de Melo, em Aracaju.

MATOS, Viviane Santos. Entrevista, concedida em 5 de julho de 2014 a Alda Valéria Santos de Melo, em Aracaju.

MELO, Alda Valéria Santos de. A formação e atuação do tradutor intérprete de Libras em sala de aula. 2013. Dissertação (Mestrado em Educação) - Universidade Tiradentes, Aracaju, 2013.

PIRES, CleidiLovatto. O intérprete de Libras: um olhar sobre a prática profissional. Seminário Desafios para o Próximo Milênio, Rio de Janeiro, RJ - 19 a 20 de setembro de 2000 - INES, p.85-86.

QUADROS, Ronice Muller de; PERLIN, Gladis (Org.). Estudos Surdos II. Petrópolis, RJ: Arara Azul, 2007. 267p. (Série Pesquisas).

QUADROS, Ronice Muller de. 0 tradutor intérprete de Língua de Sinais e Língua Portuguesa. Brasília: MEC. SEESP, 2004.

ROSA, Andréa da Silva. Entre a visibilidade da tradução de sinais e a invisibilidade da tarefa do intérprete. Dissertação (Mestrado em Educação) - Unicamp, Campinas, 2005. 
SOUSA, Joana. Crescer bilíngue: as crianças ouvintes filhas de pais surdos. Exedra: Revista Científica, Número temático - Português: Investigação e Ensino, 2012. p.404-413.
SANDER, Ricardo. O intérprete de Libras: um olhar sobre a prática profissional. Seminário Desafios para o Próximo Milênio, Rio de Janeiro, RJ - 19 a 20 de setembro de 2000 - INES p.80-81.

Recebido em: 26 de julho de 2014

Avaliado em: 20 de Fevereiro de 2014

Aceito em: 20 de março de 2015
Recebido em: 26 de Julho de 2014

Avaliado em: 20 de Fervereiro de 2014 Aceito em: 20 de Março de 2015
1. Mestre em Educação pela Universidade Tiradentes, Pós-Graduada em Educação Inclusiva, Professora das Faculdades AMADEUS e Pio Décimo, Técnica na Divisão de Educação Especial na Secretaria Estadual de Educação e membro integrante do Grupo de Pesquisa em Políticas Públicas, Gestão Socioeducativas e Formação de Professores (GPGFOP/UNIT/CNPq) -

E-mail: aldamvaleria@yahoo.com.br 
